\title{
Changing expectations
}

If we cannot control

biased media influence

from within our own

profession then we

cannot complain at the

expectations we are setting up in the public in the future
W hen I was working in general dental practice $\mathbf{3 0}$ years ago we had a regular 'gas session' every week. A local doctor would attend, and each of the three dentists (including me) would take it in turns to extract teeth all afternoon, often involving clearances. Turnaround was pretty swift with 'recovering' patients dotted around the practice, attended to by dental nurses and relatives until the patients could be taken home. What seems so amazing today is that our practice was not unusual.

The contrast between accepted practice 30 years ago and today, reflects the changing expectations of the general public. The recent publication of $A$ Conscious Decision is a interesting example of this, as we see the use of general anaesthesia in general practice disappear completely, a reflection of the changing attitudes towards GA in both the profession and the public.

Expectations are interesting concepts, because they will often result in actualities. How often do you hear 'You get what you expect' and how often is it true? Is our future decided by our expectations of today? It would appear that in dentistry our present has indeed been fashioned, in a large part, by many of the reports published in the past which have affected our expectations of the future. The report initially sets up the expectations, these form the basis of discussions and debate, the ideas gradually become accepted and finally actually happen. In effect the report has both predicted and created the future.

If this model is true then it raises the vital question 'Who is influencing the expectations of the public most at the moment?' I would suggest the obvious answer is the media, because the media actually decide what we receive in the way of information and also how that information is biased before we receive it. The past few months have seen some quite remarkable examples of media influence, ranging from the publication of pictures of convicted paedophiles in one national Sunday newspaper (with the incredible ramifications that could herald - will we see convicted speeding offenders next?) to the continued inference that the current government is only able to put a 'spin' on things rather than tell the truth; as if the media themselves were innocent of such an action.

Dentistry has had its own share of media influence recently as the letters in recent $B D J$ s demonstrate. The Dispatches debate rumbles on with most of the correspondents focusing on the clinical debate rather than the more important potential for concern that such TV reporting creates. The last issue of the BDJ contained a letter and response about The Independent's misinterpretation of Aubrey Sheiham's speech at the Dental Practice Conference and the effects it had. And recently (and inexplicably) the newspapers considered the CJD story in dentistry to be headline news.

To me what comes across in all of this is the responsibility we have (as a profession) to try and ensure we reduce bias in all media reporting to a minimum and also to ensure the public receive a clear and honest message, whether the news is good or bad. This is not as easy as it sounds as we have so little control over what the media actually reports, regardless of the information they are given, but we have to try. We would also seem to have a responsibility to keep 'our own house' in order when it comes to use of the media to further individual interests, something we currently find difficult to do.

While it remains impossible to prevent those with an agenda from using the media to further their own interests, surely we can control them if they are within the profession? Not to do so would appear to be irresponsible. After all, if we cannot control biased media influence from within our own profession then we cannot complain at the expectations we are setting up in the public in the future. 